\title{
Amsterdam tegenover Den Haag - Duisenberg's eerste verslag
}

\section{Van minister tot president}

Duisenberg zal het zich moeten laten welgevallen dat hij nog een tijd lang zal worden vergeleken met Zijlstra. Die vergelijking ligt alleen al voor de hand omdat beiden een ministerschap van financiën achter zich hadden toen zij aantraden als president van De Nederlandsche Bank (DNB). De minister van financiën en de president van de centrale bank worden in de Westerse wereld algemeen aangeduid als 'de monetaire autoriteiten'. In hun handen ligt grotendeels het lot van het geld. Wie dit eerst een tijd lang van de Haagse kant heeft bekeken blijft vermoedelijk ook in zijn Amsterdamse periode goed bekend met de Haagse benaderingswijze. Dat neemt niet weg dat Amsterdam een eigen verantwoordelijkheid en een eigen denkraam met zich meebrengt. Dat blijkt ook duidelijk uit het Jaarverslag 1981 van DNB, dat eind april verschenen is.

Omdat dit tevens het eerste jaarverslag is dat onder verantwoordelijkheid valt van de nieuwe president kan het zin hebben, de denkontwikkeling van Duisenberg gedurende zijn ministeriële periode en daarna nog even naar voren te halen.

Toen hij aantrad als minister van financiën schreven we 1973. Het was toen al duidelijk dat een eind was gekomen aan het tijdperk van ononderbroken volledige werkgelegenheid. Verder was de gedachtengang van Keynes nog oppermachtig. Daarbij kwam dat Duisenberg behoorde tot een politieke partij die opvoering van de collectieve voorzieningen hoog in haar vaandel had geschreven.

Geen wonder dat Duisenberg in de eerste jaren van zijn ministerschap een zeer grote explosie van de collectieve uitgaven moest toestaan. Dit wordt met opzet zo geformuleerd, omdat de minister van financiën in het kabinet en tegenover het parlement geacht wordt de rol van tegenstribbelaar te spelen ten aanzien van de opvoering van de staatsuitgaven. Van die rol is tot 1975 weinig terecht gekomen, al heeft Duisenberg binnenskamers misschien nog erger voorkomen. We moeten in dit verband inderdaad spreken van 'erg', want de latere ontwikkeling leerde dat het Keynesiaanse instrument bot was geworden. In plaats daarvan ging het opgeroepen hoge financieringstekort zelf verkeerd op de werkgelegenheid inwerken als gevolg van het opdrijven van de rente. Dat remde de investeringsactiviteit af en beperkte langs deze weg het tot stand komen van nieuwe arbeidsplaatsen. Toen Duisenberg in de gaten kreeg dat het kabinet waarvan hij deel 
uitmaakte op het verkeerde paard had gewed wat de financiële politiek betrof, ging hij overstag naar een meer behoedzaam beleid. Maar dat was juist binnen zijn partij uiterst moeilijk. Bovendien is er op dit gebied vrijwel geen haarspeldbocht mogelijk. Vandaar dat er alleen maar uitkwam: terugneming van gas.

$\mathrm{Na}$ het aftreden van het kabinet-Den Uyl kwam Duisenberg al snel in het particuliere bankwezen terecht. Hij was toen niet meer gebonden aan het verdedigen van de politiek waarvan zijn partij voorstandster was. Die grotere vrijheid werd door hem gebruikt door voortdurend het kabinet-Van Agt-I te manen tot veel grotere terughoudendheid op het gebied van de uitgavenpolitiek. Maar een eenmaal op gang gebracht krachtig vliegwiel laat zich moeilijk weer temmen. We zouden kunnen zeggen dat het kabinetVan Agt-I, opnieuw in termen van autorijden geformuleerd, het gaspedaal helemaal losliet.

Daarna kwam het kabinet-Van Agt-II. Duisenberg, inmiddels in afwachting van zijn benoeming tot president al vast directeur van DNB geworden, werd weer meer bij het regeerbeleid betrokken. In een bepaald stadium werd over het ontwerp-regeerakkoord de zienswijze gevraagd van enkele deskundigen, waaronder de president van DNB. Deze laatste uitte zich zeer kritisch, in het bijzonder over de te uitbundige financiële politiek die in het ontwerp-regeerakkoord was voorzien. Het desbetreffende oordeel van DNB stoelde vooral op interne voorbereiding door Duisenberg. Maar de politieke partij waartoe hij behoorde was al bij voorbaat afwijzend. Zij stelde dat zij geen behoefte had aan adviezen van economische deskundigen en dat zij er, als deze toch zouden worden ingewonnen, niet naar zou luisteren. Het kabinet-Van Agt-II liep al spoedig vast in het onvermogen, een regeringsverklaring aan de Tweede Kamer over te leggen. In dit stadium werd Duisenberg er opnieuw bij betrokken. Hem werd namelijk een lijmpoging gevraagd. Hij wees dit van de hand, omdat hij dan naar zijn oordeel later, als president van DNB, niet meer geheel vrij tegenover het eventueel herstelde kabinet-Van Agt-II zou staan. Dat standpunt is natuurlijk zeer begrijpelijk, maar toch vraagt men zich af of het landsbelang niet beter gediend was geweest met meer greep van de latere president van DNB op het financiële program van het eventueel herstelde kabinet-Van Agt-II. Hoe dit zij, het weer opgelapte kabinet trachtte de lijn van zijn voorganger en van de tweede periode van het kabinet-Den Uyl nog meer te accentueren, door echt remmend te gaan optreden wat betreft de collectieve uitgaven. Maar dat beleid werd weer grotendeels ongedaan gemaakt door tevens weer meer gas te gaan geven. Men probeerde op allerlei punten de aanvankelijk pijnlijke gevolgen van de beperking van de collectieve uitgaven te verzachten door extra uitkeringen aan de trekkers van de laagste inkomens, meer geld uit te trekken voor het scheppen van banen in de kwartaire sector en soortgelijke maatregelen. Duisenberg keert zich daar scherp tegen in zijn jaarverslag. Daarmee komen we op de inhoud van dit verslag, waarover het in de rest van dit artikel gaat. Voor een goed overzicht wordt het voorgaande nog even kort samengevat in termen van de gehanteerde beeldspraak. 
Kabinet

DEN UYL 1973 - 1975

DEN UYL 1975 - 1977

VAN AGT-I

VAN AGT-II
Uitgavenbeleid

Plankgas

Gas terugnemen

Gas loslaten

Remmen en gas geven tegelijk

\section{De president zelf}

Het spreekt vanzelf dat een jaarverslag als dat van DNB, met zeer veel feitelijke gegevens, grafieken, statistieken en ook nog alles wat het tot een jaarverslag van een naamloze vennootschap maakt, het resultaat is van een belangrijke groepsactiviteit binnen DNB.

Willen we echt de president in dit verslag aan het werk zien, dan moeten we vooral letten op het eerste gedeelte van de tekst, dat de titel 'Algemeen Overzicht' draagt. Dat beslaat niet meer dan 15 bladzijden, maar in dat beperkte kader staat vrijwel alles wat de president over het economische beleid op zijn hart heeft. Bekend is dat Zijlstra, als hij dit stuk aan het schrijven was, door niets mocht worden gestoord. Hij legde zijn hart er in. Voorzover valt na te gaan geldt dit ook voor Duisenberg, althans in die zin dat het heel duidelijk het stempel draagt van zijn oordeel. In het volgende zal dan ook vooral dit algemene overzicht op de voet worden gevolgd. $\mathrm{De}$ ordelijke rangschikking van feiten die kenmerkend is voor de rest van het algemeen-economische deel van het verslag zal er bij worden betrokken voorzover van belang ter illustratie van het hoofdbetoog. Bij dit alles zal een indeling worden gemaakt in het buitengebeuren, de economische betrekkingen met de buitenwereld, de inflatierente en investeringen, de werkgelegenheid en de overheidsfinanciën. Aan het eind zal worden getracht, lessen uit dit alles te trekken over de rol van de president in het financiële gebeuren.

\section{Het buitengebeuren}

$\mathrm{Nu}$ de werkloosheid in ons land en in de Westerse wereld van ongeveer dezelfde orde van grootte is geworden als tijdens het dieptepunt van de jaren 30 , dringt zich een nadere vergelijking op tussen toen en nu. In het jaarverslag wordt daarbij gewezen op het éne punt waar de wereldeconomie zich nog gunstig onderscheidt van 50 jaar geleden. Dat is de grotere behoedzaamheid bij het naar buiten keren van de eigen economische problemen door protectie en een wedloop in depreciatie van de wisselkoersen. Helemaal gerust kunnen we daarover echter niet zijn. Beide steken tot op zekere hoogte de kop weer op. In het jaarverslag wordt daartegen gewaarschuwd en er wordt tevens gepleit voor gezamenlijk optreden bij de bestrijding van de economische moeilijkheden.

Een bijzondere ontwikkeling heeft zich in 1981 voltrokken met betrekking tot de overschotten van de olie-exporterende landen. Hun betalingsbalansoverschot op lopende rekening nam af van ruim $\$ 100$ miljard in 1980 tot $\$ 60$ miljard in 1981. Die ontwikkeling is nog steeds aan de gang en het is niet uitgesloten dat het overschot in 1982 geheel zal zijn verdwenen. Dat 
kan leiden tot meer evenwichtige betalingsbalansen in de wereld en daardoor tot minder heftige schommelingen van de wisselkoersen. Voor het ogenblik is de tweede oliecrisis wat dit betreft dus overwonnen, maar het in de meeste landen gevoerde beleid wordt er nog steeds door gestempeld. Dat beleid verschilde vrij sterk van dat na de eerste olieschok in en kort na 1973/1974. Destijds streefde een aantal landen naar compensatie van de door de olieprijsstijging veroorzaakte vraaguitval. Nu staan inflatiebestrijding en structurele aanpassing voorop. Hierin weerspiegelen zich twee ontwikkelingen die zich inmiddels hebben voorgedaan. In de eerste plaats is, zoals reeds eerder werd gesteld, het geloof in het recept van Keynes vrijwel verdwenen. In de tweede plaats is er als gevolg van de hoog opgelopen financieringstekorten van de overheid niet of nauwelijks ruimte meer voor een politiek die gericht is op vraagherstel. Die ruimte is tijdens en na de eerste oliecrisis al verbruikt. Zelfs al zou men het anders willen, dan nog resteert nu weinig meer dan aanpassing.

Het oliegebeuren van de laatste jaren heeft er toe geleid dat de niet-olieexporterende ontwikkelingslanden in zeer sterke mate een beroep hebben gedaan op het Internationale Monetaire Fonds (IMF). In 1981 stond bij hen niet minder dan $97 \%$ van het bedrag aan totale trekkingen uit. In het jaarverslag wordt een vermanende vinger opgestoken over deze eenzijdige aanwending van de middelen van het IMF. Gewezen wordt op de wenselijkheid van meer spreiding en op het risico dat het IMF, tegen de bedoeling in, betrokken raakt in het verstrekken van ontwikkelingshulp. Daar is het niet geschikt voor, al ware het alleen al omdat het zijn middelen ter beschikking moet stellen voor het verstrekken van tijdelijke betalingsbalanssteun, onder zodanige voorwaarden dat het economische beleid van het betrokken land uitzicht biedt op herstel. Op deze wijze kan worden bijgedragen tot grotere stabiliteit van de wisselkoersen.

Ook binnen Europa bestaat er een afspraak op het gebied van de wisselkoersen. Dit is het Europese Monetaire Systeem(EMS). Het EMS waarborgt geen volstrekt stabiele onderlinge wisselkoersen, omdat de economische ontwikkeling en het economische beleid van de deelnemende landen niet voldoende gelijkgericht zijn. Daarom is er aanvankelijk veel twijfel geweest aan de zin van deze samenwerking. Toch is er in de 3 jaar waarin het systeem nu werkt weinig turbulentie op het gebied van de wisselkoersen geweest. Hebben de pessimisten dus ongelijk gekregen? Wacht even, zegt Duisenberg. Er zijn tekenen dat het vaarwater onrustiger wordt. Het is tot dusver vrij goed gegaan omdat de Duitse mark een tijd lang nogal zwak in de markt heeft gelegen. Dat werd veroorzaakt door het grote Westduitse betalingsbalanstekort i.v.m. de tweede oliecrisis. Daardoor werd de voortdurend lagere inflatiegraad in dat land overschaduwd. Het ziet er echter naar uit dat deze valuta opnieuw naar voren komt als structureel sterk en ' dat kan voortdurend tot spanningen in het wisselkoersarrangement van het EMS leiden.

$\mathrm{Er}$ is ook de invloed die uitgaat van de Amerikaanse economie en economische politiek. In het jaarverslag wordt de toon er niet opgewekter op als dit onderwerp aan de orde komt. Van de overzijde van de Atlantische Oceaan komt immers in de laatste jaren weinig dat bijdraagt tot even- 
wichtsherstel. Zowel de rentevoet als de koers van de dollar waren geen voorbeelden van stabiele grootheden. Duisenberg vraagt zich af of juist een grotere stabiliteit van de rente niet zou hebben bijgedragen tot een grotere stabiliteit van de dollarkoers en juist daardoor tot beperking van de geldgroei. Dit laatste achten de Amerikaanse autoriteiten van groot belang, maar het verwaarlozen van de eerstgenoemde grootheden, die beide belangrijke invloed uitoefenen op de rest van de wereld, heeft vermoedelijk toch niet goed gewerkt op de verwezenlijking van de voornaamste doelstelling. Daarom verwerpt Duisenberg niet langer de mogelijkheid dat de Europese landen gezamenlijk hun beleid tot terugdringing van de inflatie en de overheidstekorten coördineren, ten einde onafhankelijker te worden van het Amerikaanse renteverloop. Dat klinkt nogal wat anders dan de uitlating van Zijlstra hierover in het vorige jaarverslag. Daarin werd gesteld dat de hoge rente een bittere vrucht is van de inflatie en dat rentestanden niet naar beneden kunnen worden gepraat, ook niet door overleg op het hoogste politieke niveau.

Als laatste punt t.a.v. het buitengebeuren wordt gewezen op de traditionele vergelijking tussen de ontwikkeling van een aantal belangrijke economische grootheden in Nederland en in de buitenwereld. In de eerste plaats trekt het sterk achterblijven van de Nederlandse lonen bij die van de voornaamste concurrenten de aandacht. Na 1978 is de stijging niet minder dan 18 procentpunten daarbij achtergebleven. Bij deze vergelijking is gecorrigeerd voor wisselkoerswijzigingen, maar die zijn in de betrokken periode van veel minder betekenis geweest dan vanaf 1970 tot 1978. Daar staat tegenover dat de collectieve uitgaven in Nederland als percentage van het nationale inkomen nog steeds ver tot vrij ver boven het overeenkomstige percentage in de belangrijkste Westerse landen liggen. Het gemiddelde voor die landen ligt in de orde van grootte van 45 a 50 , terwijl Nederland de 60 is gepasseerd.

\section{De betalingsbalans}

Het economische buitengebeuren komt ons land binnen via de betalingsbalans. De betalingsbalans op lopende rekening wordt gedomineerd door de handelsbalans en de dienstenbalans.

Beide hebben in het afgelopen jaar opmerkelijke ontwikkelingen te zien gegeven. De handelsbalans gaf een sterke omslag te zien, vooral voortvloeiend uit een stijging van het uitvoervolume buiten de energiesector met 4-\% en een even grote daling van het invoervolume buiten de energiesector. De ruilvoet van dit goederenverkeer vertoonde een lichte daling. Het saldo in het energieverkeer veranderde weinig. Aan beide kanten daalde het volume vrij sterk, maar de ruilvoet onderging enige verbetering.

De daling van het invoervolume is niet iets om ons op de borst te slaan. $\mathrm{Zij}$ weerspiegelt namelijk in belangrijke mate de verdere achteruitgang van de binnenlandse economische activiteit. Als gevolg daarvan liepen de investeringen vrij sterk terug en werd tevens belangrijk op voorraden ingeteerd. De stijging van het uitvoervolume steekt gunstig af bij de toeneming van het wereldhandelsvolume. Dat moet vooral worden toegeschreven aan de reeds genoemde verbetering van de Nederlandse concurrentiepositie, ge- 
meten aan de loonkosten. Toch zou men in het licht van de zeer aanzienlijke verbetering die heeft plaats gevonden een verdergaande vooruitgang van het uitvoervolume hebben verwacht. Er zijn echter enkele tegenwerkende factoren, zoals een uit groei-oogpunt enigszins ongunstige samenstelling van zowel het Nederlandse uitvoerpakket als het Nederlandse uitvoerlandenpatroon, alsmede de relatief hoge Nederlandse energieprijzen.

Bij de dienstenbalans vallen twee dingen op. In de eerste plaats ondergingen de netto ontvangsten uit vervoer een vrij belangrijke stijging. Verwacht mag echter worden dat dit berust op een prijsstijging die zich niet verder zal doorzetten. In de tweede plaats vertoonden de netto ontvangsten uit het reisverkeer voor het eerst sinds lange tijd weer een daling van het nadelige saldo. Deze ontwikkeling kwam van weerskanten tot stand, want de uitgaven daalden en de ontvangsten stegen. Wat het kapitaalverkeer met het buitenland betreft werden reeds geruime tijd bestaande ontwikkelingen verder doorgetrokken. Zo bleven de directe Nederlandse investeringen in het buitenland in hoog tempo doorgaan en daalden de buitenlandse investeringen in Nederland verder. Beide kunnen in belangrijke mate worden toegeschreven aan het betrekkelijk ongunstige vestigings- en investeringsklimaat in Nederland.

\section{Inflatie, rente en investeringen}

In het economische proces hangt alles met alles samen. Dat maakt het dikwijls moeilijk, zinvolle indelingen te maken. Aan de andere kant eist de ordening der gedachten dat niet alles er uit komt te zien als één brij. Wat de samenhang tussen inflatie, rente en investeringen betreft is er echter reden, deze onder één hoofd op te voeren.

De inflatie in Nederland is in de jaren 70 gedempt door de stijging van de koers van de gulden. Daar tegenover is ook de ontwikkeling van de lonen gematigder verlopen dan gemiddeld in de voornaamste concurrerende landen. Per saldo is er een verbetering van de concurrentiepositie overgeschoten. Het is dus blijkbaar niet zo dat loonmatiging zinloos is wegens extra stijging van de koers van de gulden. De sterke positie van de gulden heeft ook tot gevolg gehad dat vooral in de laatste tijd de rente in Nederland minder hoog is opgelopen dan gemiddeld in de rest van de Westerse industrielanden. Dat is nóg een reden, sterkte van de gulden, voorzover wij daar iets aan kunnen doen, hoog in ons vaandel te schrijven. Wat het huidige tempo van de inflatie betreft tekent zich een stabilisatie op ruim $6 \frac{1 \%}{\%}$ per jaar af. Op West-Duitsland na is dit het laagste niveau in de Europese gemeenschap. Maar dat land moet wel sterk in de gaten worden gehouden, want het is verreweg ons voornaamste buitenlandse afzetgebied en tevens op andere exportmarkten een belangrijke concurrent. Met name de loonontwikkeling gaat daar duidelijk gematigder in haar werk dan bij ons. In verband met dit alles steekt ook het rentepeil er gunstig af.

Met ons andere buurland is het juist veel slechter gesteld dan bij ons. Dat komt nog nader ter sprake.

De rente is toch hoog genoeg om sterk remmend in te werken op de 
investeringsactiviteit in de particuliere sector. Tevens gaat het lang niet naar wens met de arbeidsinkomensquote, als maatstaf voor de rentabiliteit van het bedrijfsleven. De zgn. gecorrigeerde arbeidsinkomensquote, d.i. globaal gesproken de arbeidsinkomensquote van het particuliere bedrijfsleven, liep in 1981 verder op tot $92 \%$, in de industrie zelfs tot $97 \%$.

Geen wonder dat het al lage peil van de bruto investeringen in vaste bedrijfsactiva in 1981 weer fors daalde, namelijk met $14 \%$. Langzamerhand geeft dit aanleiding tot bezorgdheid over de mate van vernieuwing van ons produktiepotentieel, met het oog op de werkgelegenheid in de toekomst.

\section{Werkgelegenheid}

Onder werkgelegenheid wordt in dit verband verstaan alles wat betrekking heeft op de aanwending van de produktiefactor arbeid, dus ook werkloosheid en arbeidsduur.

De werkgelegenheid in bedrijven nam in het verslagjaar sterk af. Deze daling was vooral geconcentreerd in de bouwnijverheid. Voor het eerst daalde ook de werkgelegenheid in de commerciële dienstensector. In de semi-commerciële dienstensector nam de werkgelegenheid enigszins toe, evenals bij de overheid. Deze laatste toeneming was echter kleiner dan in voorgaande jaren.

De effectieve personeelsbezetting daalde in veel geringere mate, als gevolg van de verdere afneming van het ziekteverzuim.

De stijging van de werkloosheid was veel groter dan overeenkomt met de daling van de werkgelegenheid. Dat komt door de sterke toeneming van het arbeidsaanbod, en wel met 60.000 arbeidsjaren. De lengte van de werkweek is in 1981 gemiddeld niet veranderd. Wel is het aantal vakantiedagen en het gebruik van VUT-regelingen toegenomen.

Werktijdverkorting als middel tot werkloosheidsbestrijding richt zich in de laatste tijd vooral op het scheppen van deeltijdbanen. Het is echter de vraag of de omstandigheden daarvoor thans gunstig zijn. Veelzeggend is dat het aantal deeltijdbanen in 1981 niet verder is toegenomen. De uitbreiding die eerder plaats vond voltrok zich in een stadium van toenemende werkgelegenheid. Dan is het blijkbaar mogelijk, nieuwe banen te richten op deeltijdwerk. Bij afneming van de werkgelegenheid is deze dynamiek er niet. Verder zal een opzettelijke opvoering snel op thans nog latente knelpunten kunnen stuiten. Tevens mag worden verwacht dat de inkomensderving voor een deel zal worden gecompenseerd door extra aanbod van arbeid van andere gezinsleden. In zoverre stijgt wel de werkgelegenheid, maar daalt niet de werkloosheid. Dit alles brengt met zich mee dat in het jaarverslag weinig wordt verwacht van deze vorm van arbeidstijdverkorting. Voor meer algemene arbeidstijdverkorting gelden, wil zij inderdaad leiden tot verdeling van werk zonder aantasting van de totale hoeveelheid werk, zodanig strikte voorwaarden dat er vermoedelijk weinig effectieve mogelijkheden zijn. Daarover is uitvoerig uitgeweid in het vorige jaarverslag. 


\section{Overheidsfinanciën}

De president komt pas goed op dreef als hij de ontwikkeling van de overheidsfinanciën ter sprake brengt. Vooral de verdere groei van het financieringstekort is een ontwikkeling die hem kennelijk niet vrolijk makkt. Gesproken wordt van de toenemende dreiging dat het een onbeheerst proces wordt en van onmacht om orde op zaken te stellen. Alleen het aardgas staat nog tussen ons en de situatie in België, maar gesteld wordt dat België dichterbij is dan men denkt.

De toon is dus nog wat scherper geworden dan toen Zijlstra de Haagse politici de oren waste, maar misschien had ook Zijlstra in deze omstandigheden zich nog rechtstreekser dan vroeger tegen het financiële regeringsbeleid gekeerd.

De deplorabele staat van de overheidsfinanciën bemoeilijkt het economische herstel. Deze negatieve invloed werkt vooral via het grote beslag dat de overheid op de kapitaalmarkt legt. In 1981 haalde de overheid, met inbegrip van de weggemoffelde financiering van de bouw van woningwetwoningen, niet minder dan rond twee derde van alle aanbod ter kapitaalmarkt naar zich toe, tegen een derde in 1979.

Betekent dit dat meer monetaire financiering van het tekort toch het minste kwaad is? Nee, zegt Duisenberg. Afgezien van verdere storingen die hiervan uit zouden gaan maakt dit geen verschil. Ook bij geldschepping moet er immers geleend worden, en wel van de geldscheppende instellingen. Zelfs in het extreme geval van meer renteloos lenen bij de Nederlandsche Bank moeten de kosten voor de staat toch becijferd worden op de orde van grootte van de rente die hiermee wordt uitgespaard. In diezelfde mate daalt immers de winst van de Bank. Deze wordt nagenoeg in zijn geheel aan de staat uitbetaald, want die is de enige aandeelhouder.

De overheid treft ook zichzelf zwaar door het laten voortduren van het gapende financieringstekort. De rentebetalingen voor opgenomen leningen en op in hogere rentepercentages omgezette bestaande leningen nemen zo sterk toe dat zij zelf een belangrijke bepalende factor voor de omvang van het tekort worden. Het wordt daardoor voortdurend moeilijker, uit deze fatale spiraal te springen. $\mathrm{Nu}$ bedragen zij al ongeveer een derde van het tekort. Wanneer dit laatste verder als percentage van het nationale inkomen gelijk blijft en het huidige rentepeil aanhoudt, zullen de rentebetalingen aan het eind van de jaren 80 even groot zijn als nu het hele tekort bedraagt! Kan de president nu niet rechttrekken wat het kabinet scheeftrekt? Vrijwel niet. De monetaire politiek kan niet worden beschouwd als een tweede slot op de deur. Een politiek van krap geld in omstandigheden als deze zou verschillende problemen nog verergeren. Dat geldt met name voor het rentepeil en daarmee voor de investeringen en de werkloosheid. Op dit gebied gaat de Bank dan ook erg voorzichtig te werk. Zij richt zich in hoofdzaak op de liquiditeitsquote, d.i. het aandeel van de totale liquiditeitenmassa in het nationale inkomen. Naar een daling van deze quote wordt alleen gestreefd voorzover duidelijk is dat er enige speling is in de voorziening met liquiditeiten. Voor het overige kan de Bank weinig anders doen dan de liquiditeitenmassa zodanig te laten toenemen dat daarmee niet alleen een eventuele volumetoeneming van de economische activiteit, maar 
ook de zich voltrekkende inflatie kan worden gefinancierd. De draai naar de regel van de vaste geldgroei aan de hand van de produktiestijging in termen van volume, zoals het monetarisme die aanbeveelt, is moeilijk te nemen.

\section{Moraal}

In een dorpje in het Oosten van het land was een nieuwe dominee aangetreden die met veel vuur de aanval opende op de gezapigheid van zijn gemeenteleden. Die spraken over de preek bij het uitgaan van de kerk. Wat zij er van vonden kwam hier op neer: wat kan dominee het mooi zeggen! Toen dat dominee ter ore kwam was hij daar zeer mee verguld. Maar hij zat er een eind naast. Als hij meer weet had gehad van de mentaliteit van zijn mensen zou hij juist erg ontmoedigd hebben moeten zijn. Het rustige mensentype in die streken drijft de zaken meestal niet op de spits. Zij gaan liefst alle problemen uit de weg en willen dominee daarom niet voor het hoofd stoten. Maar zij storen zich in het geheel niet aan hem en gaan volkomen hun eigen gang. Wat zij met hun vriendelijk aandoende uitspraak bedoelen is: laat dominee maar kletsen.

Men voelt waar het heen gaat. Nederland, en in het bijzonder Den Haag, heeft veel weg van een Saksisch dorp bij de beoordeling van de boodschap van de president van de centrale bank. Met name de vooraanstaande politici zeggen: prachtig, maar ze doen er niets aan. Voor volgend jaar kan men al voorspellen hoe het weer zal gaan: rampzalig, zegt Duisenberg, goed gezegd, menen degenen die voor de rampzalige toestand verantwoordelijk zijn.

Dit wil niet zeggen dat het jaarverslag helemaal geen weerstand oproept. $\mathrm{Er}$ is nog een achterhoedegevecht aan de gang van degenen die middelen willen inzetten om op korte termijn de werkloosheid te bestrijden, ten koste van een nog groter financieringstekort. Daartegen heeft Duisenberg zich al van tevoren ingedekt. Hij keert zich tegen de politiek van het kabinet-Van Agt-II, die sterk gericht was op bezuinigingen, welke vervolgens weer werden begeleid met geld kostende maatregelen die er op waren gericht, de gevolgen van de bezuinigingen te verzachten. Als op deze wijze steeds de zwakken in de samenleving worden ontzien komen er voortdurend nieuwe zwakken, die dezelfde rechten doen gelden. Daardoor blijven we in de problemen.

In zekere zin is de boodschap van Duisenberg natuurlijk eenzijdig, en ook dat wordt hem van bepaalde zijde verweten. Als algemeen antwoord kan worden gesteld dat dit ook de bedoeling is, want het is zijn opdracht, vooral te letten op handhaving van de waarde van het geld naar binnen en naar buiten. Daarnaast is het van belang, op te merken dat deze eenzijdigheid nu kleiner is dan ooit, omdat alle belangrijke doelstellingen van economische politiek vrijwel op één lijn zijn komen te liggen: zoek eerst gezonde overheidsfinanciën en alle andere dingen zullen $U$ worden toegeworpen! Het is dus een heilzame eenzijdigheid, want als we doen wat Duisenberg aanbeveelt worden we er op den duur allemaal beter van. 
Het is er nu natuurlijk niet het goede moment voor, maar ik vraag mij wel eens af of het geen aanbeveling verdient dat de Tweede Kamer het kabinet duchtig aan de tand voelt over het jaarverslag van De Nederlandsche Bank. Daarin wordt, vooral in de laatste jaren, een zo scherpe en gedocumenteerde kritiek op het regeerbeleid gegeven, dat er toch alle aanleiding is, het kabinet te vragen, een standpunt daarover te bepalen en dat als discussiestuk aan de Kamer voor te leggen. Dan komt de kritiek vermoedelijk veel beter tot haar recht en krijgt het jaarverslag ook indirect een rol te spelen in het regeerbeleid. Zoals het nu is, kunnen docenten in de economie er geruime tijd van doen, maar voor de rest is het jaarverslag na een week weer vergeten. Dat is erg jammer, want hier staat in hoe het moet. Ook de publikaties van het Centraal Planbureau zijn natuurlijk in vele gevallen kritisch van toon, want ieder die op economisch gebied nadenkt, heeft weinig goede woorden over voor het economische beleid van de laatste jaren. Het Planbureau is echter als ambtelijke instelling in mindere mate in staat, een onafhankelijk geluid te laten horen.

Samenvattend zouden we kunnen zeggen: degenen die het weten, dragen geen regeringsverantwoordelijkheid en degenen die regeringsverantwoordelijkheid dragen, zien geen kans, gebruik te maken van de deskundige adviezen die hun worden aangereikt. 